DOI:10.2478/rrlm-2019-0012

\title{
Prevalence of a Iodothyronine Deiodinase 2 gene single nucleotide polymorphism in children with congenital hypothyroidism from Western Romania and impact on TSH levels
}

\author{
Niculina Mang ${ }^{1}$, Liviu Athos Tămas²*, Otilia Mărginean ${ }^{1}$, Cătălin Marian², Sorin
} Ursoniu $^{3}$, Andrei Anghel ${ }^{2}$

1. Department of Pediatrics, "Victor Babes" University of Medicine and Pharmacy, Timisoara, Romania

2. Department of Biochemistry and Pharmacology, "Victor Babes" University of Medicine and Pharmacy, Timisoara, Romania

3. Department of Public Health Medicine, "Victor Babes" University of Medicine and Pharmacy,

Timisoara, Romania

\begin{abstract}
The aim of this study was to evaluate the prevalence of the Iodothyronine Deiodinase 2 gene Thr92Ala polymorphism in children from West of Romania with congenital hypothyroidism (CH) and association with TSH levels in response to levothyroxine monotherapy.

Genotyping in 50 children with $\mathrm{CH}$ and 52 healthy controls was done using real time PCR.

The results showed that there was no statistical difference between the frequencies of genotypes in patients vs. controls. Patients were treated with L-thyroxine and most had normal values for fT3 and fT4. However, high TSH values were found in 21 patients (42\%) after treatment. Among patients with high TSH values, AA genotypes were significantly more prevalent $(p=0.044)$ than TT and AT genotypes. Our results suggest that for the D2 gene Ala92Thr polymorphism, the AA genotype may be detrimental for achieving euthyroidism in patients with $\mathrm{CH}$ and levothyroxine monotherapy, therefore polytherapy could be considered as a better approach in these patients.
\end{abstract}

Keywords: congenital hypothyroidism, deiodinase type 2, endocrine disorder, gene polymorphism

Received: $6^{\text {th }}$ November 2018; Accepted: $7^{\text {th }}$ January 2019; Published: $17^{\text {th }}$ January 2019

\section{Introduction}

Congenital hypothyroidism $(\mathrm{CH})$ is the most common genetic endocrine disorder and a frequent cause of preventable mental retardation
$(1,2)$. It has an average incidence of 1:3000 to 1:4000 newborns, which varies by geographic location. The majority of cases $(80-85 \%)$ are caused by thyroid dysgenesis (abnormalities of

\footnotetext{
*Corresponding author: Liviu Athos Tămas, "Victor Babes" University of Medicine and Pharmacy, Timisoara,
} Romania. E-mail: tliviu33@yahoo.com 
thyroid gland development and migration) but a significant number of cases, $10-15 \%$, appear due to inherited defects in thyroid hormone synthesis pathways (thyroid dyshormonogenesis) $(2,3)$. Other causes of $\mathrm{CH}$ are defects of TSH production or peripheral defects in thyroid hormone metabolism caused by mutations in genes encoding thyroid hormone plasma membrane transporters like monocarboxylate transporter 8 (MCT8), thyroid hormone receptor $\beta$ - TR $\beta$ and deiodinases $(4,5,6)$.

Deiodinases are selenoenzymes that catalyze the conversion of thyroxin (T4) into triiodothyronine (T3) (7). There are 3 types of deiodinases with different localisation and expression. Type 1 deiodinase (D1) is synthesized and expressed in cells from the thyroid gland, liver, kidney, and pituitary gland, being responsible for the blood levels of triiodothyronine (the circulating form of T3) $(8,9)$. Type 2 deiodinase (D2) is an enzyme which catalyzes the intracellular conversion of T4 to its active form T3 in many types of tissues such as the pituitary gland, central nervous system, cardiac and skeletal muscle, brown adipose tissue, and placenta; in liver and kidney there are lower levels of expression for D2 $(10,11)$. Therefore, D2 has a main role in local $\mathrm{T} 3$ conversion from $\mathrm{T} 4$ having also a regulating effect for specific metabolic activity of tissues $(12,13,14)$. Type 3 deiodinase (D3) which is expressed in the central nervous system and placenta, can be considered an inactivating enzyme because it converts $\mathrm{T} 4$ and $\mathrm{T} 3$ to products without a known biological activity like reverse triiodothyronine (rT3) and 3,3'-diiodothyronine (T2).

Some recent studies showed that the polymorphism of human D2 gene may modify the synthesis of thyroid hormones; a single nucleotide polymorphism $(\mathrm{A} / \mathrm{G})$ will result in threonine (Thr) to alanine (Ala) replacement in codon 92 (D2 Thr92Ala). The homozygous subjects with Ala/ Ala genotype seem to have a lower activity of
D2 in tissues compared to heterozygous subjects with Ala/Thr genotype and homozygous subjects with Thr/Thr genotype. Therefore, the T3 effects for homozygous subjects with Ala/Ala genotype in tissues where a D2 gene expression is present will be reduced, the enzyme having a lower activity (15).

In addition, some studies showed that the D2 Thr92Ala polymorphism can be associated with many other disorders, such as Graves' disease, osteoarthritis, hypertension, and disorders related to the central nervous system like bipolar disorder, depression, and cognitive impairment. Also, many studies have shown that the Thr92Ala polymorphism may be related to metabolic disorders like type 2 diabetes mellitus (T2DM) and insulin resistance, having an effect on the body mass index (BMI) $(16,17)$.

The fundamental role of thyroid hormones on brain functions was recognized by the connection between the impairment of cognitive functions and untreated patients with $\mathrm{CH}$.

In hypothyroidism almost $12 \%$ of all patients treated with levothyroxine will achieve normal serum levels of TSH (euthyroidism) but continue to have residual symptoms of hypothyroidism, such as psychological and metabolic effects $(18,19)$. This finding represents a major public-health concern considering the relatively high prevalence of hypothyroidism and the fact that levothyroxine monotherapy is unsuccessful in restoring all the parameters to normal ranges. (20).

Even if the aetiology of this phenomenon is not fully understood there are several theories which were investigated. One of these hypotheses consider that the serum levels of T3 might not be fully returned to normal values among such patients due to an insufficient T4 to T3 conversion at tissue level by deiodinases which could explain why a minority stay symptomatic despite the treatment with levothyroxine (21). There are some adult patients who display an improved 
well-being when co-administered levothyroxine and liothyronine; nevertheless the majority of clinical trials have failed to demonstrate that such a combination therapy has an objective benefit. Therefore, in $\mathrm{CH}$ with resistance to standard treatment with levothyroxine the D2 gene polymorphism could have an important role (22). In children, where the central nervous system and cognitive functions need normal serum and cellular levels of both thyroid hormones in order to develop properly, it's especially important to identify any cause which could induce a deficit of $\mathrm{T} 3$ in the case of a standard treatment for $\mathrm{CH}$.

The aim of this study was to evaluate the prevalence of D2 Thr92Ala polymorphism in children from Western Romania with congenital hypothyroidism treated with a standard levothyroxine therapy.

\section{Materials and Methods}

\section{Patients}

Following written informed consent from their legal representatives consistent with the Helsinki declaration, the patients group was composed from 50 children with congenital hypothyroidism with ages from 0 to 18 years $(58 \%$ were less than one year old and $22 \%$ older than 6 years), hospitalized in the Paediatric Clinic Nr. 1 Timisoara. All the patients had a specific treatment with L-Thyroxine (levothyroxine) which was administrated immediately after the diagnosis, following a positive result in $\mathrm{CH}$ neonatal screening. The control group was composed of 52 children with ages from 0 to 18 years hospitalized in the Paediatric Clinic Nr. 1 Timisoara for other types of pathology, excluding thyroid-related pathology. Only two children in the control group were less than one year old and had a negative result in $\mathrm{CH}$ neonatal screening. The rest of the children were at least 3 years old ( $80 \%$ were older than 6 years) with no medical history of $\mathrm{CH}$ or other types of hypothyroidism. This study was approved by the Ethical Committee of Paediatric Clinic Nr. 1 Timisoara, no. 70/21.12.2016.

Blood samples were collected during a period of one year, from 2016 to 2017 from patients and controls. Venous blood (100 - $200 \mu \mathrm{L})$ was used for genotyping and plasma for biochemical tests. In the patient group the concentrations of free thyroid hormones and TSH were measured by an electro-chemiluminescence immunoassay (ECLIA) on anADVIA Centaur CP Immunoassay System analyzer (Siemens): TSH (normal range was $0.62-8.05 \mathrm{mU} / \mathrm{L}$ or $0.54-4.53 \mathrm{mU} / \mathrm{L}$ depending on the reagent type), free triiodothyronine (fT3, the reference range was $3.5-7.7$ $\mathrm{pmol} / \mathrm{L}$ ) and free thyroxin (fT4, the reference range was $6.2-30.1 \mathrm{pmol} / \mathrm{L})$. In the control group, due to the age of subjects and their negative medical history of thyroid-related pathology the measurement of free thyroid hormones (fT3 and fT4) was not performed, only TSH concentration was determined as inclusion criteria and all subjects had normal values within the reference range.

\section{DNA genotyping}

Genomic DNA was extracted from a volume of $200 \mu \mathrm{L}$ venous blood with QIAamp DNA Blood Mini Kit (Qiagen) using the methodology described by the manufacturer's instructions. After isolation, DNA concentration and purity was assessed by measuring the absorbance of each sample at $260 \mathrm{~nm}$ and $280 \mathrm{~nm}$ with a NanoDrop ND-1000 spectrophotometer (Thermo Fisher Scientific). To evaluate the purity and protein contamination of DNA samples the A260/A280 ratio was calculated and values greater than 1.8 were considered adequate.

The method used for DNA samples genotyping was Real Time PCR with MGB Taqman probes (TaqMan Pre-designed SNP Genotyping Assay, Life Technologies, rs225014) (23) which have 
an augmented melting temperature (Tm) and offer better allelic sequence discrimination due to a specific minor groove binder (MGB). The amplification reaction was performed on a AB7900HT Fast Real Time PCT System using a program with an initial stage of DNA polymerase activation for 10 minutes at $95^{\circ} \mathrm{C}$, followed by 45 cycles consisting of two steps: DNA denaturation for 15 seconds at $95^{\circ} \mathrm{C}$ and annealing continued with extension for 1 minute at $60^{\circ} \mathrm{C}$.

The amplification reaction mixture consisted of a variable volume of each DNA sample with an optimal quantity of genomic DNA (1 to maximum $10 \mathrm{ng}$ ) and $12.5 \mu \mathrm{l}$ Genotyping Master Mix which included the DNA polymerase (AmpliTaq Gold DNA Polymerase), deoxyribonucleotide triphosphates, buffer components. A volume of $0.63 \mu \mathrm{l}$ TaqMan probes (with two different fluorophores, 6-FAM and VIC) was then added and nuclease free water up to a final volume of $25 \mu$.

\section{Statistical Analysis.}

The results were expressed as frequencies and mean \pm S.D.

Allelic frequencies of $\mathrm{T}$ and A alleles were determined by gene counting, and possible deviations from the Hardy-Weinberg equilibrium (24) were verified using a $\chi 2$ test. Clinical and laboratory data were addressed using Pearson's $\chi 2$ test,
Mann-Whitney U-test, Kruskal-Wallis test. A two-tailed $\mathrm{P}<0.05$ was considered statistically significant, and all analyses were conducted in Stata/MP version 15 (StataCorp LLC, College Station, TX)

\section{Results}

The genotyping results of patients' group with congenital hypothyroidism (50 subjects) and controls' group (52 subjects) are presented in Table 1. The allele specific discrimination of genotypes by Real Time PCR with Taqman probes was highly reliable for patients and controls (Figure 1 and Figure 2); however there were a few samples that didn't meet the quality control threshold and were re-analyzed.

The frequency of A-allele (92 Alanine) in patients with $\mathrm{CH}$ was 0.350 and similar with the frequency in the control group (0.365).

In the patients' group, 25 patients $(50 \%)$ were homozygous (TT genotype) for the T-allele (92 Threonine), 15 (30\%) had heterozygous genotypes (TA), and $10(20 \%)$ were homozygous for the A-allele (AA). In the control group, 22 subjects $(42.3 \%)$ had the TT genotype, 22 (42.3\%) were heterozygous (TA), and $8(15.4 \%)$ had the AA genotype.

The genotypes in the group of patients with $\mathrm{CH}$ were not in Hardy- Weinberg equilibrium (the

Table 1. Demographic variables and characteristics of the cases and controls

\begin{tabular}{|c|c|c|c|c|}
\hline \multicolumn{2}{|c|}{ Characteristics } & Cases $(\mathrm{N}=50)$ & Controls $(\mathrm{N}=52)$ & p val. \\
\hline \multicolumn{2}{|c|}{ Female, N (\%) } & $28(56 \%)$ & $25(49 \%)$ & 0.482 \\
\hline \multicolumn{2}{|c|}{ Age (years)* } & $0.25(0.16-4.91)$ & $9.33(6.16-14.33)$ & $<0.001$ \\
\hline \multicolumn{2}{|c|}{ fT3 $(\mathrm{pmol} / \mathrm{L})^{*}$} & $7.015(6.39-7.75)$ & ND & \\
\hline \multicolumn{2}{|c|}{ fT4 $(\mathrm{pmol} / \mathrm{L})^{*}$} & $16.05(14.65-18.01)$ & ND & \\
\hline \multicolumn{2}{|c|}{$\mathrm{TSH}(\mathrm{uUI} / \mathrm{mL})^{*}$} & $5.7(2.97-9.86)$ & $\mathrm{NV}$ & \\
\hline \multirow{5}{*}{ Thr92Ala } & $\mathrm{T}$ allele frequency, $\mathrm{N}(\%)$ & $65(65 \%)$ & $66(63.5 \%)$ & \multirow{2}{*}{0.819} \\
\hline & A allele frequency, $\mathrm{N}(\%)$ & $35(35 \%)$ & $38(36.5 \%)$ & \\
\hline & TT genotype & $25(50 \%)$ & $22(42.3 \%)$ & \multirow{3}{*}{0.428} \\
\hline & AT genotype & $15(30 \%)$ & $22(42.3 \%)$ & \\
\hline & AA genotype & $10(20 \%)$ & $8(15.4 \%)$ & \\
\hline
\end{tabular}

*Data is presented as median (IQR) except where otherwise stated; ND-not determined; NV-normal values 


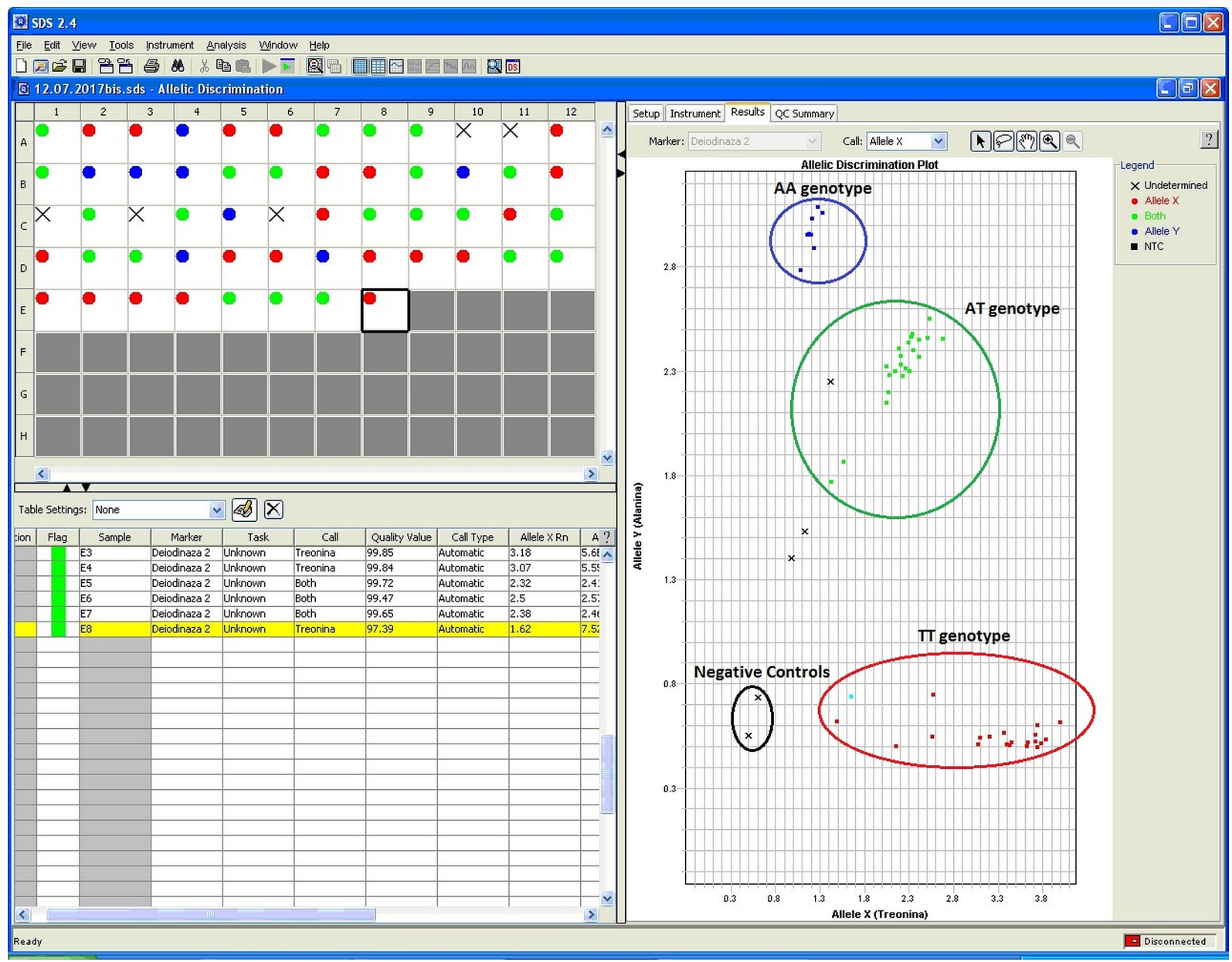

Fig. 1. Specific allelic discrimination of homozygous (AA and TT) and heterozygous (AT) genotypes in control group by Real Time PCR with Taqman probes

expected frequencies for patients were: $\mathrm{AT}=$ $45.50 \%$, $\mathrm{TT}=42.25 \%$, AA $=12.25 \%$ ), which could be explained by the low frequency of A-allele and the reduced number of patients included in the study. However, in the control group, the identified genotypes were in Hardy-Weinberg equilibrium (the expected frequencies for controls were: $\mathrm{AT}=46.35 \%, \mathrm{TT}=40.3 \%, \mathrm{AA}=$ $13.35 \%)$. There was no statistical difference between the frequencies of genotypes in patients' group vs. control group.

In all the patients with a positive result in $\mathrm{CH}$ neonatal screening, the venous concentrations of thyroid hormones and TSH were measured and according to results the treatment with L-tyroxine was initiated. An initial dose of $10-12 \mu \mathrm{g} / \mathrm{kg}$ per day was administered with a first follow-up examination after one week. Then the initial dose was adjusted depending on TSH, fT3 and fT4 determinations results and subsequent evaluations were performed after two weeks or one month. In older patients who already had a positive diagnostic of $\mathrm{CH}$ the treatment was personalized with variable doses of levothyroxine. As consequence the majority (44 subjects) had normal values for fT3 and 


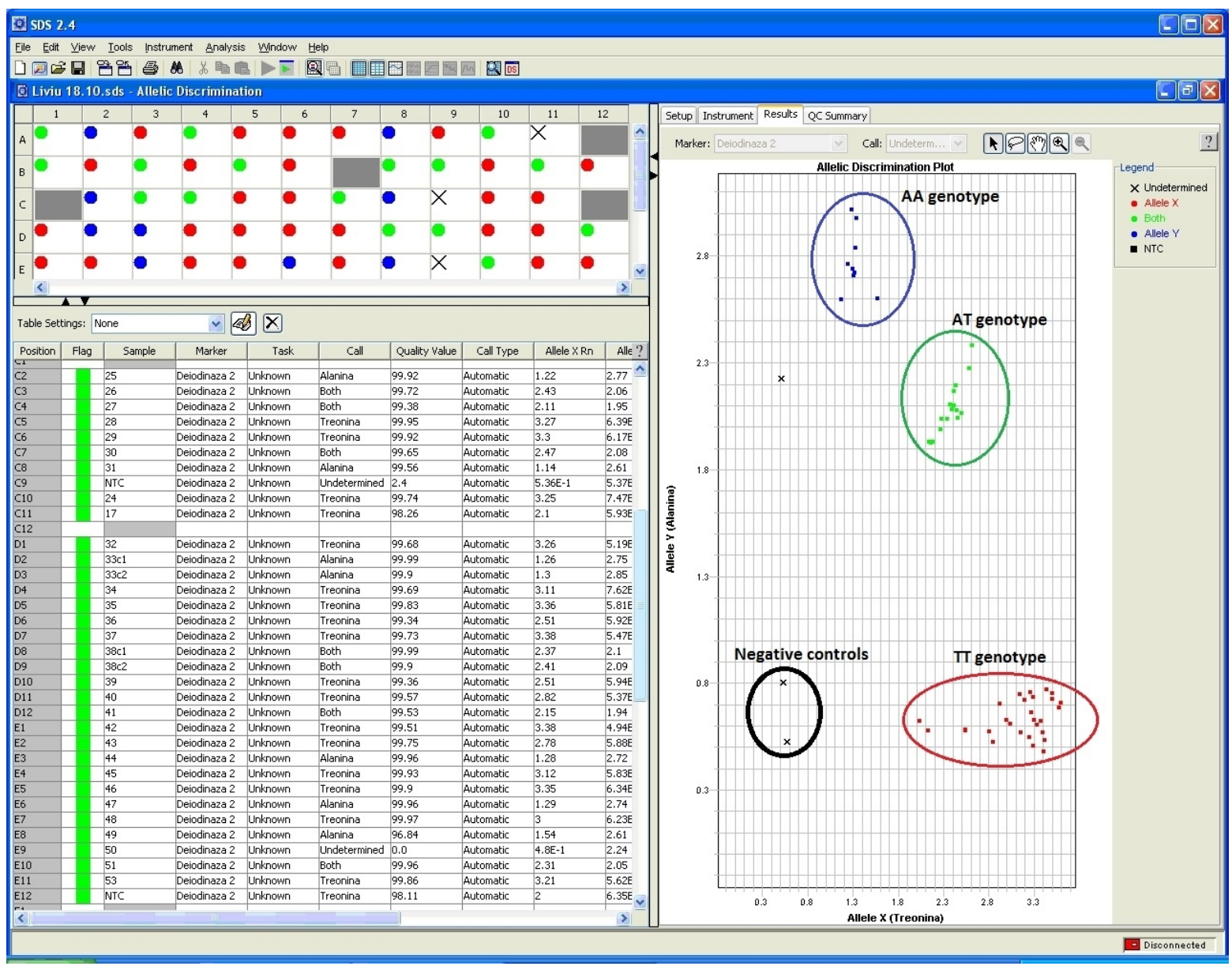

Fig. 2. Specific allelic discrimination of homozygous (AA and TT) and heterozygous (AT) genotypes in patients group by Real Time PCR with Taqman probes

fT4. However, high values for TSH were found in 21 patients $(42 \%)$, which were not normalized by the treatment. 6 patients had TSH values greater than $100 \mathrm{mU} / \mathrm{L}$, and the rest had mild serum TSH elevations -12 patients with TSH values within the interval $8.43-14.47 \mathrm{mU} / \mathrm{L}$ ( $>8.05 \mathrm{mU} / \mathrm{L})$, one patient had a TSH value of
$28.84 \mathrm{mU} / \mathrm{L}$ and two patients had TSH values greater than $4.53 \mathrm{mU} / \mathrm{L}(7.46$ and $5.23 \mathrm{mU} / \mathrm{L})$. The fraction of patients with high TSH values in patients with AA genotype was significantly higher $(p=0.044)$ than the fraction of patients with high TSH values in patients with TT and AT genotype (Table 2).

Table 2. Distribution of TSH values according to patients' genotype

\begin{tabular}{lccc}
\hline Genotype & Normal TSH & High TSH & p val. \\
\hline TT, N (\%) & $14(56 \%)$ & $11(44 \%)$ & \\
\hline AT, N (\%) & $12(80 \%)$ & $3(20 \%)$ & 0.044 \\
\hline AA, N (\%) & $3(30 \%)$ & $7(70 \%)$ & \\
\hline
\end{tabular}

High $\mathrm{TSH} \geq 4.53 \mathrm{mUI} / \mathrm{L}$ or $\geq 8.05 \mathrm{mUI} / \mathrm{L}$ 
Only 6 treated patients presented abnormal values of fT 3 and fT 4 but none of these had the AA genotype, so no relationship between these parameters could be assessed.

\section{Discussion}

Even though both groups, patients and controls, had a relatively small number of subjects, the allele frequency of Thr92Ala D2 polymorphism found in this study (35\% for the patients group and $36.5 \%$ for the control group) is quite similar to those reported previously: $38.8 \%$ in a study with 158 healthy blood donors and $40.4 \%$ in a study of 141 adult patients with autoimmune primary hypothyroidism $(25,26)$.

Several studies showed an association of the Thr92Ala D2 polymorphism with a reduced action of thyroid hormones at various organ targets. Also, some ex vivo data from other studies suggest that a defective D2 enzyme with a modified activity is encoded by the A-allele (26,27).

However, the influence of the Thr92Ala polymorphism on blood levels of thyroid hormones is rather controversial. In a pharmacogenomic study, Butler et al showed that the AA genotype is associated with a lower rate of T3 release from the thyroid following TSH stimulation, a finding consistent with a decrease in intrathyroidal deiodination (21).

In another recent study, Torlontano et al. showed that athyreotic patients with a homozygous AA genotype will need higher doses of T4 replacement therapy to achieve the suppression of serum $\mathrm{TSH}$. The conclusion of these findings was that in TSH producing pituitary cells (thyrotropes) there may be a reduced activity of D2 (27).

Another study by Peeters et al. on TSH levels in heterozygous subjects (26) for the Thr92Ala D2 polymorphism found significantly lower plasma TSH levels, but there was no association with circulating levels of iodothyronine and a fol- low-up study (28) confirmed this finding also in elderly subjects $(26,28)$.

The functional D2 activity in patients with an Ala92Ala genotype is lower and less T3 will be produced in tissues. Animal studies on rats showed that in the brain, up to $80 \%$ of intracellular T3 (29) is produced by local deiodination of circulating $\mathrm{T} 4$ which enters the astrocytes and it's transformed by D2 in T3 and then transported into the neurons. For other tissues expressing D2 activity, more then $50 \%$ of T3 derives of circulating T4 (30). Therefore, the Thr92Ala D2 polymorphism may influence the T3 content in the brain, which depends more than other tissues on the deiodination process without obvious changes in concentrations of circulating thyroid hormones.

However, one study with a limited sample size of 141 adult patients (18-70 years of age) with autoimmune primary hypothyroidism showed that the D2 Thr92Ala SNP was not associated with an improvement of well-being, neurocognitive functioning and a preference for combined L-T4 + L-T3 therapy (25). Another, larger study among 552 adult patients on L-T4 replacement reported positive results - the polymorphism may affect the psychological well-being of patients and can predict which patients will have an improved well-being in response to combination therapy with T3 (30).

All these studies included adult patients with hypothyroidism in which the nervous system development is already complete, but for children with $\mathrm{CH}$ and a developing nervous system, the inadequate quantity of T3 in the nervous cells, even with a levothyroxine monotherapy starting immediately after birth, could be critical for further development $(31,32,33)$.

The higher percentage of patients with AA genotype having abnormal TSH values but normalized fT4 and fT3 values could indicate that the insufficient conversion of T3 in T4 due to the lower D2 activity is a signal for hypothyroid- 
ism at cellular level which triggers a higher TSH secretion. However, in infants and children with $\mathrm{CH}$ treated with levothyroxine, the thyroid hormone resistance (THR) is frequent (43\% for children less than one year old) and even if fT4 concentrations are normalized by treatment within the reference range, elevated serum TSH concentrations over the upper limit of the reference range are frequently encountered $(34,35)$. The causes of THR are not fully understood, but mutations in the genes of all T3 nuclear receptors (TR $\alpha 1, T R \beta 1$, and TR $\beta 2)$ are one of the main causes beside defective deiodinases or membrane transporters (36). Molecular analysis of TR genes or other genes with relevance in the pathogenesis of thyroid hormone resistance was not performed, therefore we cannot exclude that in some cases this type of defects are accountable for THR. This could represent a limitation of our study, even if the frequency of D2 Thr92Ala polymorphism should be greater than the frequency of TR gene mutations (unknown in Romanian population). Another limitation of this study remains the sample size of cases and controls which could limit generalizability of the results to the general population.

In conclusion, the results of this study suggest that the AA genotype for the D2 gene polymorphism may be detrimental for achieving euthyroidism in patients with congenital hypothyroidism and levothyroxine monotherapy.

Consequently, for children in the first years of life, when euthyroidism is essential for a normal development of nervous system and the evaluation of levothyroxine monotherapy effects on cognitive capacity is difficult and incomplete, a combined therapy - levothyroxine plus triiodothyronine could be valuable for achieving euthyroidism and a better nervous system response to therapy $(37,38)$.

The results also provide further evidence for implication of genetic factors in differences between therapy responses for $\mathrm{CH}$ patients and may represent the rationale for a personalized therapy.

\section{Authors' contributions}

The concept of the study was done by AA. NM and LT performed the literature search. NM, LT and OM performed investigations, data collection and processing. AA, CM, LT and SU participated in data analysis and interpretation. AA, CM and LT drafted the manuscript. All authors had read and approved the final manuscript.

\section{Conflicts of interest}

The authors declare no conflict of interest.

\section{Abbreviations}

$\mathrm{CH}$ - congenital hypothyroidism

MCT8 - monocarboxylate transporter 8

T4 - thyroxin

T3 - triiodothyronine

D1 - type 1 deiodinase

D2 - type 2 deiodinase

D3 - type 3 deiodinase

rT3 - reverse triiodothyronine

T2 - 3,3'-diiodothyronine

$\mathrm{Thr}$ - threonine

Ala - alanine

T2DM - type 2 diabetes mellitus

BMI - body mass index

THR - thyroid hormone resistance

\section{References}

1. Büyükgebiz A. Newborn screening for congenital hypothyroidism. J Clin Res Pediatr Endocrinol. 2013;5 Suppl 1:8-12

2. Rastogi MV, LaFranchi SH. Congenital hypothyroidism. Orphanet J Rare Dis. 2010;5:17. DOI: 10.1186/1750-1172-5-17

3. Gaudino R, Garel C, Czernichow P, Léger J. Proportion of various types of thyroid disorders among newborns with congenital hypothyroidism and normally located gland: a regional cohort study. Clin Endocrinol (Oxf). 2005;62(4):444-8. DOI: 10.1111/j.13652265.2005.02239.x 
4. Anastasovska V, Koviloska R, Kocova M. High incidence of congenital hypothyroidism in one region of the Republic of Macedonia. Balkan J Med Genet. 2014;17(1):31-6. DOI: 10.2478/bjmg-2014-0024

5. Kara C, Günindi F, Can Y1lmaz G, Aydın M. Transient congenital hypothyroidism in Turkey: an analysis on frequency and natural course. J Clin Res Pediatr Endocrinol. 2016;8(2):170-9. DOI: 10.4274/jcrpe. 2345

6. Grasberger H, Refetoff S. Genetic causes of congenital hypothyroidism due to dyshormonogenesis. Curr Opin Pediatr. 2011;23(4):421-8. DOI: 10.1097/ MOP.0b013e32834726a4

7. Senese R, Cioffi F, de Lange P, Goglia F, Lanni A. Thyroid: biological actions of 'nonclassical' thyroid hormones. J Endocrinol. 2014;221(2):R1-12. DOI: 10.1530/JOE-13-0573

8. Gnidehou S, Caillou B, Talbot M, Ohayon R, Kaniewski J, Noël-Hudson MS, et al. Iodotyrosine dehalogenase 1 (DEHAL1) is a transmembrane protein involved in the recycling of iodide close to the thyroglobulin iodination site. FASEB J. 2004;18(13):1574-6. DOI: 10.1096/fj.04-2023fje

9. Maia AL, Goemann IM, Meyer EL, Wajner SM. Deiodinases: the balance of thyroid hormone: type 1 iodothyronine deiodinase in human physiology and disease. J Endocrinol. 2011;209(3):283-97. DOI: 10.1530/JOE10-0481

10. Bianco AC, Kim BW. Deiodinases: implications of the local control of thyroid hormone action. J Clin Invest. 2006;116(10):2571-9. DOI: 10.1172/JCI29812

11. Dentice M, Salvatore D. Deiodinases: the balance of thyroid hormone: local impact of thyroid hormone inactivation. J Endocrinol. 2011;209(3):273-82. DOI: 10.1530/JOE-11-0002

12. Arrojo E Drigo R, Bianco AC. Type 2 deiodinase at the crossroads of thyroid hormone action. Int $\mathrm{J}$ Biochem Cell Biol. 2011;43(10):1432-4. DOI: 10.1016/j.biocel.2011.05.016

13. Arrojo E Drigo R, Fonseca TL, Werneck-de-Castro JP, Bianco AC. Role of the type 2 iodothyronine deiodinase (D2) in the control of thyroid hormone signalling. Biochim Biophys Acta. 2013;1830(7):3956-64. DOI: 10.1016/j.bbagen.2012.08.019

14. Dentice M, Marsili A, Zavacki A, Larsen PR, Salvatore D. The deiodinases and the control of intracellular thyroid hormone signaling during cellular differentiation. Biochim Biophys Acta. 2013;1830(7):3937-45. DOI: 10.1016/j.bbagen.2012.05.007

15. Alina B, Daria P, Olga F, Vladislav S, Anna K, Elena G. Thr92Ala polymorphism of human type 2 deiodinase gene (hD2) affects the development of Graves' disease, treatment efficiency, and rate of remission. Clin Dev Immunol. 2012;2012:340542. DOI: 10.1155/2012/340542

16. Verloop H, Dekkers OM, Peeters RP1, Schoones JW, Smit JW. Genetics in endocrinology: genetic variation in deiodinases: a systematic review of potential clinical effects in humans, Eur J Endocrinol. 2014;171(3):R12335. DOI: 10.1530/EJE-14-0302

17. McAninch EA, Jo S, Preite NZ, Farkas E, Mohácsik $\mathrm{P}$, Fekete $\mathrm{C}$, et al. Prevalent polymorphism in thyroid hormone-activating enzyme leaves a genetic fingerprint that underlies associated clinical syndromes. J Clin Endocrinol Metab. 2015;100(3):920-33. DOI: 10.1210/ jc. 2014-4092

18. Dilli D, Çzbaş S, Acıcan D, Yamak N, Ertek M, Dilmen U. Establishment and development of a national newborn screening programme for congenital hypothyroidism in Turkey. J Clin Res Pediatr Endocrinol. 2013;5(2):73-9. DOI: 10.4274/Jcrpe.929

19. Carlé A, Faber J, Steffensen R, Laurberg P, Nygaard B. Hypothyroid Patients Encoding Combined MCT10 and DIO2 Gene Polymorphisms May Prefer L-T3 + L-T4 Combination Treatment - Data Using a Blind, Randomized, Clinical Study. Eur Thyroid J. 2017;6(3):143-151. DOI: $10.1159 / 000469709$

20. Oto Y, Muroya K, Hanakawa J, Asakura Y, Adachi M. The ratio of serum free triiodothyronine to free thyroxine in children: a retrospective database survey of healthy short individuals and patients with severe thyroid hypoplasia or central hypothyroidism. Thyroid Res. 2015;8:10. DOI: 10.1186/s13044-015-0023-5

21. Butler PW, Smith SM, Linderman JD, Brychta RJ, Alberobello AT, Dubaz OM, et al. The Thr92Ala 5' type 2 deiodinase gene polymorphism is associated with a delayed triiodothyronine secretion in response to the thyrotropin-releasing hormone-stimulation test: a pharmacogenomic study. Thyroid. 2010;20(12):1407-12. DOI: $10.1089 /$ thy. 2010.0244

22. Wartofsky L. Combination L-T3 and L-T4 therapy for hypothyroidism., Curr Opin Endocrinol Diabetes Obes. 2013;20(5):460-6. DOI: 10.1097/01. med.0000432611.03732.49

23. Simionescu R, Cherecheanu A, Voinea L, Sfrenț-Cornățeanu R. TNF- $\alpha$ Gene Polymorphisms and Primary Open Angle Glaucoma in Romanian Population. Rev Romana Med Lab. 2015; 23(1): 47-58. DOI: 10.1515/rrlm-2015-0004

24. Anghel A, Enache A, Seclaman E, Gruin G, Ursoniu S, Alexa A, et al. Genetic polymorphism data on 15 autosomal STR markers in a Western Romanian population sample. Leg Med (Tokyo). 2014;16(4):238-40. DOI: 10.1016/j.legalmed.2014.04.001

25. Appelhof BC, Peeters RP, Wiersinga WM, Visser TJ, Wekking EM, Huyser J, et al. Polymorphisms in type 2 deiodinase are not associated with well-being, neurocognitive functioning, and preference for combined thyroxine/3,5,3'-triiodothyronine therapy. J Clin Endocrinol Metab. 2005;90(11):6296-9. DOI: 10.1210/ jc.2005-0451

26. Peeters RP, van Toor H, Klootwijk W, de Rijke YB, 
Kuiper GG, Uitterlinden AG, et al. Polymorphisms in thyroid hormone pathway genes are associated with plasma TSH and iodothyronine levels in healthy subjects. J Clin Endocrinol Metab. 2003;88(6):2880-8. DOI: $10.1210 /$ jc.2002-021592

27. Torlontano M, Durante C, Torrente I, Crocetti U, Augello G, Ronga G, et al. Type 2 deiodinase polymorphism (threonine 92 alanine) predicts L-thyroxine dose to achieve target thyrotropin levels in thyroidectomized patients. J Clin Endocrinol Metab. 2008;93(3):910-3. DOI: $10.1210 /$ jc. 2007-1067

28. Peeters RP, van den Beld AW, Attalki H, Toor Hv, de Rijke YB, Kuiper GG, et al. A new polymorphism in the type II deiodinase gene is associated with circulating thyroid hormone parameters. Am J Physiol Endocrinol Metab. 2005;289:E75-E81 DOI: 10.1152/ajpendo.00571.2004

29. Bernal J. Thyroid Hormones in Brain Development and Function. De Groot LJ, Chrousos G, Dungan K, et al., editors. Endotext (Internet). South Dartmouth (MA): MDText.com, Inc.; 2000. https://www.ncbi.nlm.nih. gov/books/NBK285549/ (Updated 2015 Sep 2).

30. Panicker V, Saravanan P, Vaidya B, Evans J, Hattersley AT, Frayling TM, et al. Common variation in the DIO2 gene predicts baseline psychological well-being and response to combination thyroxine plus triiodothyronine therapy in hypothyroid patients. J Clin Endocrinol Metab. 2009;94(5):1623-9. DOI: 10.1210/jc.2008-1301

31. McDermott MT. Does combination T4 and T3 therapy make sense?, Endocr Pract. 2012;18(5):750-7. DOI: 10.4158/EP12076.RA

32. Korkmaz L, Akın MA, Güneş T, Daar G, Baştuğ O,
Y1k1lmaz A, et al. Unusual course of congenital hypothyroidism and route of the L-thyroxine treatment in a preterm newborn. J Clin Res Pediatr Endocrinol. 2014;6(3):177-9. DOI: 10.4274/jcrpe. 1383

33. Wiersinga WM, Duntas L, Fadeyev V, Nygaard B, Vanderpump MP. 2012 ETA Guidelines: The Use of L-T4 + L-T3 in the Treatment of Hypothyroidism, Eur Thyroid J. 2012;1(2):55-71. DOI: 10.1159/000339444

34. Fisher DA, Schoen EJ, La Franchi S, Mandel SH, Nelson JC, Carlton EI, et al. The hypothalamic-pituitary-thyroid negative feedback control axis in children with treated congenital hypothyroidism. J Clin Endocrinol Metab. 2000;85(8):2722-7. DOI: 10.1210/ jcem.85.8.6718

35. Kempers MJ, van Trotsenburg AS, van Tijn DA, Bakker E, Wiedijk BM, Endert E, et al. Disturbance of the fetal thyroid hormone state has long-term consequences for treatment of thyroidal and central congenital hypothyroidism. J Clin Endocrinol Metab. 2005;90(7):4094100. DOI: $10.1210 /$ jc.2005-0197

36. van Mullem AA, Visser TJ, Peeters RP. Clinical Consequences of Mutations in Thyroid Hormone Receptor- $\alpha 1$. Eur Thyroid J. 2014; 3(1): 17-24. DOI: 10.1159/000360637

37. Wiersinga WM. Therapy of endocrine disease: T4+T3 combination therapy: is there a true effect?. Eur J Endocrinol. 2017;177(6):R287-R296. DOI: 10.1530/EJE17-0645

38. Biondi B, Wartofsky L. Combination treatment with T4 and T3: toward personalized replacement therapy in hypothyroidism?. J Clin Endocrinol Metab. 2012;97(7):2256-71. DOI: 10.1210/jc.2011-3399 